\title{
Ground Penetrating Radar Survey of Dam Structures of Kazakhstan on example of Aktobe and Karatomar Water Storage Basins
}

\author{
Zhumabek Zhantayev, Baurzhan Kurmanov, Nikolai Breusov, Shigayev Dauren, Kirsanov Alexandr \\ Department of Geophysical and Geodynamic Monitoring, LLP "Institute of Ionosphere", Almaty, Kazakhstan \\ Email: nckit@spaceres.kz,dashigaev@gmail.com
}

Received 2013

\begin{abstract}
Ground penetrating radar surveys of technical condition of Karatomar and Aktobe water storage basins on the river Tobol are shown. In this article we have shown that dams have problems with cavities and identified longitudinal dimensions of anomalous zones of decompression.
\end{abstract}

Keywords: Ground Penetrating Radar (GPR); Hydraulic Structures; Anomalous Zones; Dam; Decompression Zone; Areas of High Humidity

\section{Introduction}

Authors have examined about 30 reservoirs in Kazakhstan. Below the reservoir are large dams, which highlight the most significant anomalous zones. Investigation of grounds lying at the base of hydraulic structures, including the dynamic changes of ground properties during long-term use, is a timely and very important task. Changing of the properties of grounds, that lies in the base of the dam may lead to the settlement and destruction of hydraulic structure and if these changes are not taken into account in the design decisions during the construction, the danger of over-voltage of anomalous zones springs up, which could lead to shift of the body and the building elements of the dam. When the value of stresses and displacements exiting for the limit values of specified security criteria, the state of hydraulic structures in general may become an emergency. [1] Analysis of experience of using of various methods showed that the GPR method provides to receive a more detailed picture of the geological structure of the subject area on continuous sections compared to the traditional methods.[2]

GPR is widespread and acute in construction and geotechnical firms of most highly developed countries, such as Russia, USA, Canada, Sweden, Korea, etc. The method is based on the difference of rock on dielectric capacitivity. Emit pulses propagating in the survey environment or object are reflected from the boundary, on which change the electrical properties-electrical conductivity and dielectric capacitivity. The reflected signal is received by the receiving antenna, amplified, digitized and stored. [3]

To get decompactification zones and zones of anomalies in the soil of dam embankment on longitudinal profiles on the crest and slopes of dams, along with traditional methods (seismic and geoelectric survey) used ground penetrating radar sounding which is a more modern, high-tech and informative tool of non-destructive measurements, allows to get results in real time [2].

\section{Goals and Objectives}

The necessary of sensing caused by prolonged exploitation of water storage basins, which are built of loam and gravel-pebble material. Filtration flow and changes in curve of depression of water saturation with time gives rise to dangerous of overvoltage of anomalous zones, which could lead to a shift of the body and the elements of the dam building. [4]

\section{Method}

In the process of GPR survey of Karatomar and Aktobe water storage basins the following main stages of sensing carried out:

- Construction of GPR profiling on the axis of the dam, where shown a more general picture of structure of the dam;

- Construction of GPR profiles along the upper side of the dam, where the most visible filtration flows and decompactification zones in the body of the dam. [5]

Karatomar water storage basin was built in 1965. Pro- 
jected volume of the reservoir is 586.0 million $\mathrm{m}^{3}$. Channel type of water storage basin. The dam by maximum height of $18 \mathrm{~m}$ and width along the ridge up to 10 meters, is composed of three parts: the precoat to integration with the right bank by length $1420 \mathrm{~m}$, bulk to integration with the left bank by length 240 meters and the central rollway by length 134 meters and consists 7 spans.

Aktobe water storage basin is located to $8 \mathrm{~km}$ to south from Aktobe, in the middle reaches of Ilek River. Earthen dam is bulk of sandy-gravelly loam soil with loamy screen and diaphragm of the clay wall. Mark of the dam crest is $234.20 \mathrm{~m}$, width of the crest is 10 meters. Fastening of the top escarpment is made of reinforced concrete slabs. Reservoir fills since 1985 . Reservoir area is 3570 ha, the total water volume is 245 million $\mathrm{m}^{3}$, the effective water volume is 220 million $\mathrm{m}^{3}$.

In the process of GPR profiling on Karatomar water storage basin were conducted eight longitudinal profiles by lenght 200 - 250 meters along the crest and the upper reach of the dam, by depth of sounding over 10 meters (Figure 1).

When the GPR profiling Aktobe reservoir held 90 longitudinal and cross sections along the ridge and the upper reach of the dam, the probing depth is of about 8 meters (Figure 2).

\section{Conclusions}

The main result and the more prominent of them was the definition of anomalous zones profile No 0003 on Karatomarskomu reservoir (Figure 3).

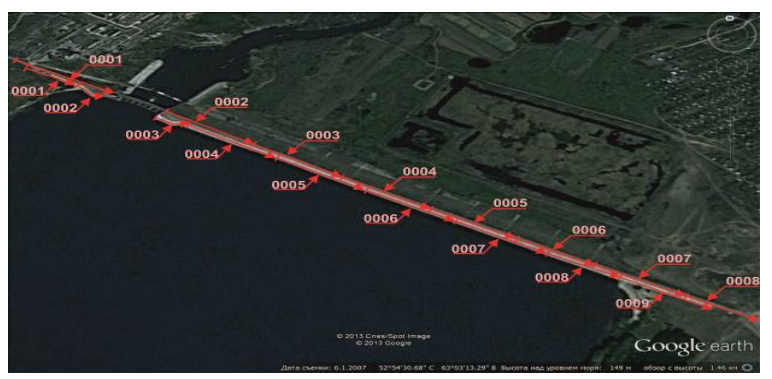

Figure 1 Location of GPR profiles by Karatomarskomu reservoir.

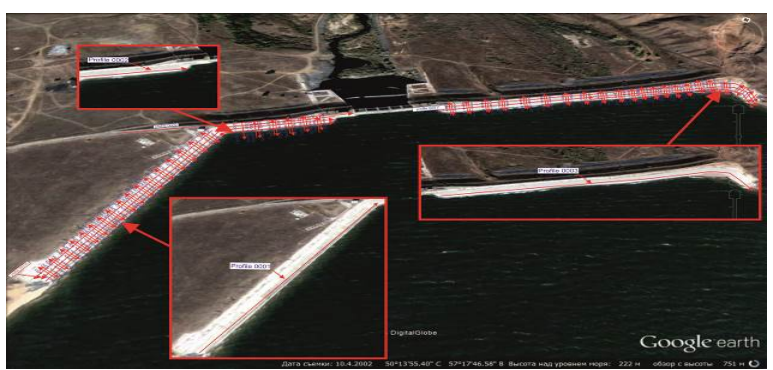

Figure 2. Location of GPR profiles of Aktobe reservoir.
Conclusion Geosciences using ground penetrating radar "OKO-2" AB-400 profile 0003 by Karatomarskomu reservoir.

The processing and interpretation of GPR profile No 0003 (Figure 3) had a decompression zone and areas of high humidity in the dam body. On GPR profiles clearly evident geological layers and boundaries decompression in points from 160 to 215 meters at a depth of up to 6 meters from the level of the crest of the dam. The probing depth of 6 meters is achieved by increasing the accumulation of signals in the longitudinal profile. Fixed boundary of the zone of distribution, which is redistributed in the soil stress state, leads to the development of cracks in the transverse directions of the gap relative to the longitudinal axis of the dam. The concept of "decompression zone" in this terminology means that the soil in this area is less denser than the surrounding layers. Cavities (voids) in the base are missing, because they have a characteristic "radiopicture" - often repeating the signal due to multipath waves in the cavity, which is the performance of work were found. It also showed very high humidity in the area of the dam body at around 115 - 155 meters depth penetration of up to 2 meters, which can also lead to anomalous zones in the dam body.

From these profiles were selected profile № 0001, 0002, 0003 by Headwater Aktobe reservoirs, which are most suitable for data analysis, identification of anomalous zones, areas of distribution (Figures 4, 5 and 6)

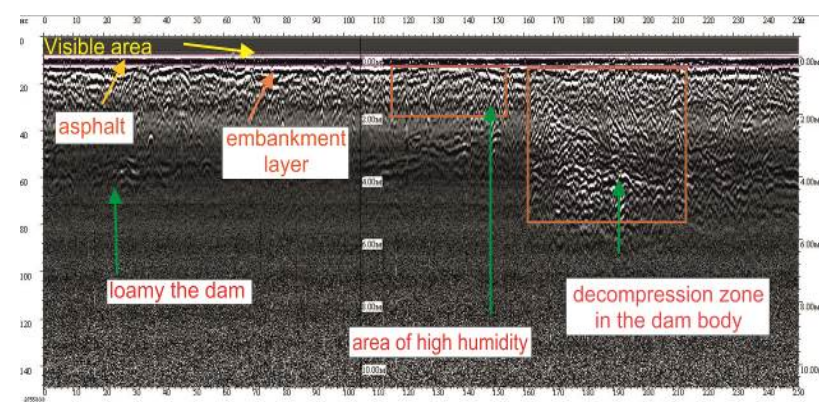

Figure 3. Longitudinal profile 0003 section of the reservoir Karatomar.

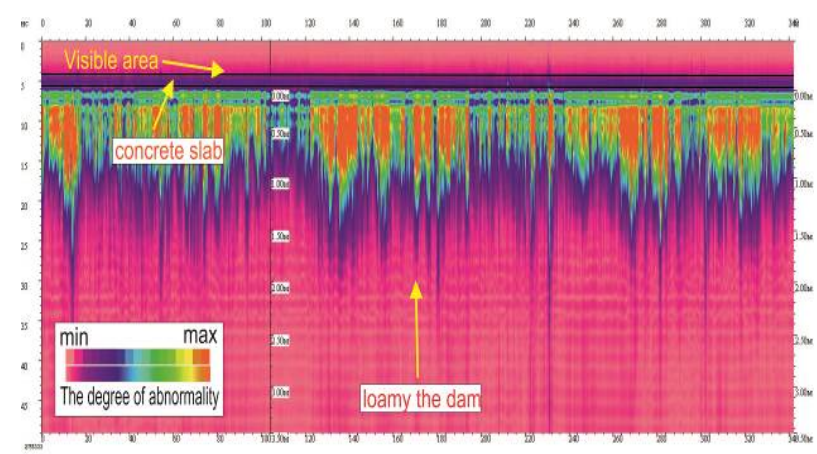

Figure 4. The longitudinal profile 0001 of the upstream Aktobe reservoir. 


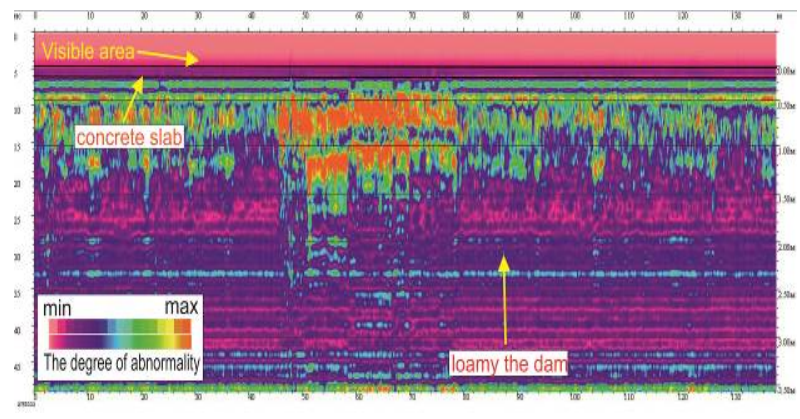

Figure 5. Longitudinal profile 0002 of the upstream reservoir Aktobe.

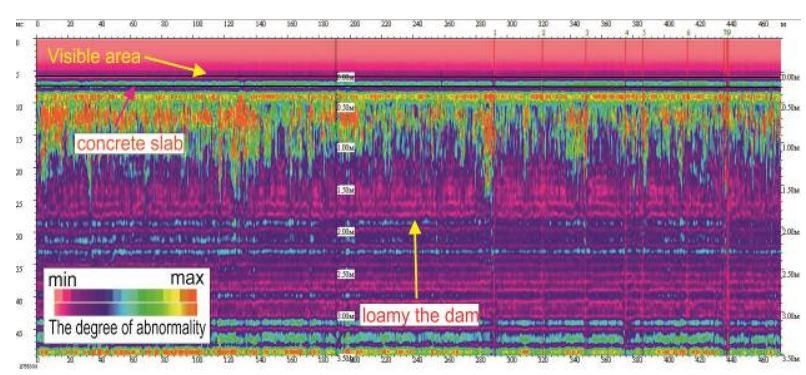

Figure 6. The longitudinal profile 0003 of the upstream reservoir Aktobe.

The processing and interpretation of GPR profile 0001 (Figure 4) were found decompression zone and areas of high humidity in the dam body. On GPR profiles clearly evident in the intense colors degree anomaly. These anomalies include voids under concrete slabs, which are filled with water, which leads to a gradual decompaction structure of the dam. Fixed boundary of the zone of distribution, at which the ground state of stress redistribution, leading to the development of cavities and fissures divide transversely to the longitudinal axis of the dam. Also in the body of the dam showed many moisture, which can lead to anomalous zones in the dam body.

The processing and interpretation of GPR profile 0002 (Figure 5) were found decompression zone and areas of high humidity in the dam body. On GPR profiles clearly evident in the intense colors degree anomaly. Anomalies include voids under concrete slabs, which are filled with water, which leads to decompaction of the dam structure. Also showed the boundary of the zone of distribution, at which the ground is a redistribution of the stress state, leading to the development of cavities and cracks gap in the transverse direction relative to the longitudinal axis of the dam. In the body of the dam is fixed high moisture content, which can lead to the formation of anomalous zones in the dam body.

The processing and interpretation of GPR profile 0003
(Figure 6), and found decompression zone damp locations in the body of the dam. On GPR profiles clearly evident in the intense colors degree anomaly. Anomalies include voids under concrete slabs, which are filled with water, which leads to decompaction of the dam structure. Fixed boundary of the zone of distribution, at which the ground state of stress redistribution, leading to the development of cavities and fissures divide transversely to the longitudinal axis of the dam. Also in the body of the dam revealed a high content of moisture, which can lead to the formation of abnormal areas in the body of the dam.

These results support the hypothesis of filtration processes and leaching sandy loam soil with gravel screen diaphragm mud wall in the location of the anomalous zones and suffusion removal of soil from the base of the dam as a result of the hydrodynamic effects of the cyclical filling and emptying of the reservoir.

Analysis of GPR profiles confirmed the possibility of using non-destructive methods for subsurface sounding dams with sufficient reliability of the data and their quantitative and qualitative interpretation. On the dynamics of the process of deformation of rock mass area of interest, was evidenced by the monitor for a few years. [6]

\section{REFERENCES}

[1] M. A. Kolosov, K. P. Morgunov and G. V. Kogan, "Ispolzovanie GPR soil testing methods vosnovany lock chamber," the Journal of the University of Water Communications, No. 4, 2009, pp. 29-33.

[2] A. Salamov and F. G. Gabibov, "The Study of Landslide Processes Bail Slope in Baku by Vertical Electrical Sounding," Engineering Survey, No. 11, 2010, pp. 36-41.

[3] M. A. Bandurin, "Survey of Irrigation Channels Through Azov Irrigation System of Non-Destructive Methods," Scientific journal KubSAU, Vol. 24, No. 8, 2006. pp. 67-73.

[4] R. M. Narayanan and J. W. Jakub, "Railroad Track Modulus Estimation Using Ground Penetrating Radar (GPR)," Railway Engineering, Proceedings of 5th International Conference, London, 4-6 July 2002, Engineering Technics Press, UK, CD-Rom.

[5] T. R. Sussmann, "Application of Ground Penetrating Radar to Railway Track Substructure Maintenance Management," Doctoral Dissertation, University of Massachusetts Amherst, 1999.

[6] G. Gallagher, Q. Leiper, M. Clark and M. Forde, "Ballast Evaluation Using Ground Penetrating Radar," Railway Gazette International, Feb, 2000, pp. 101-102. 